See Article page 1618.

\section{Commentary: The kintsugi philosophy: Embrace the imperfection of pulmonary stenosis}

\author{
Ermelinda Borrelli, MD, ${ }^{\mathrm{a}}$ and Mauro Lo Rito, $\mathrm{MD}^{\mathrm{b}}$
}

Kintsugi philosophy espouses assessing broken objects carefully before considering them useless. Kotani and colleagues ${ }^{1}$ investigate the usefulness of treating pulmonary artery coarctation (PACoA) at the time of palliative procedure in terms of ability to reach the complete repair, pulmonary artery growth, and the recurrence of PA plasty. PACoA is a well-known condition in which the ductal tissue causes a narrowing of the PA and therefore may jeopardize PA growth or the possibility of a complete repair. ${ }^{2}$ We all look to find the perfect PA plasty technique or patch material in our daily practice. Still, the reality is that reinterventions for recurrent PA stenosis are common, ${ }^{3,4}$ making the decision to treat PACoA extremely challenging.

Kotani and colleagues ${ }^{1}$ compare patients without PACoA to patients with PACoA, and within this latter group, those in whom a PA plasty was performed are compared with patients who were not treated. Indication to PA plasty in PACoA was a discrete narrowing of the PA with a diameter $<2 \mathrm{~mm}$ on echocardiogram. Patients with PACoA, treated or not, have the same rate of definitive repair compared with patients without PACoA. At the same time, in the PACoA group, the PA plasty did not show any benefit in terms of catch-up growth or reduction of reinterventions. Should we rethink surgical timing for PA plasty? Should we postpone treatment so we may adopt a hybrid strategy,

\footnotetext{
From the ${ }^{\text {a Unit of }}$ Cardiac Surgery, Intrathoracic Transplantation and Pulmonary Hypertension, University of Pavia School of Medicine, Foundation IRCCS Policlinico San Matteo, Pavia, Italy; and ${ }^{\mathrm{b}}$ Department of Congenital Cardiac Surgery, IRCCS Policlinico San Donato, San Donato Milanese, Italy.

Disclosures: The authors reported no conflicts of interest.

The Journal policy requires editors and reviewers to disclose conflicts of interest and to decline handling or reviewing manuscripts for which they may have a conflict of interest. The editors and reviewers of this article have no conflicts of interest.

Received for publication Oct 10, 2021; revisions received Oct 10, 2021; accepted for publication Oct 13, 2021; available ahead of print Oct 20, 2021.

Address for reprints: Mauro Lo Rito, MD, Department of Congenital Cardiac Surgery, IRCCS Policlinico San Donato, Piazza Edmondo Malan, 2, 20097, San Donato Milanese, Italy (E-mail: mauro.lorito@gmail.com).

J Thorac Cardiovasc Surg 2022;163:1627

$0022-5223 / \$ 36.00$

Copyright (c) 2021 by The American Association for Thoracic Surgery

https://doi.org/10.1016/j.jtcvs.2021.10.016
}

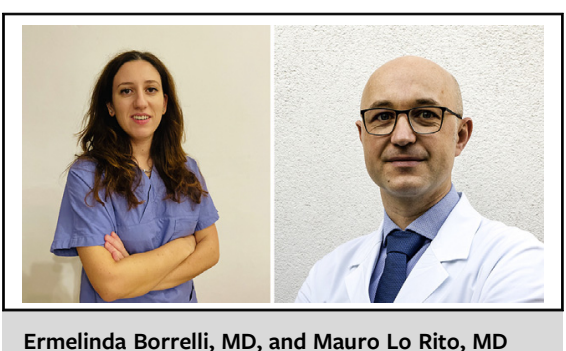

Ermelinda Borrelli, MD, and Mauro Lo Rito, MD

$$
\begin{aligned}
& \text { CENTRAL MESSAge } \\
& \text { Pulmonary artery plasty for PA- } \\
& \text { CoA at initial palliation is not gold } \\
& \text { dust that restores a broken pul- } \\
& \text { monary artery. But it is the only } \\
& \text { glue we have knowing that we } \\
& \text { may not always donate beauty. }
\end{aligned}
$$

considering that intraoperative PA stenting seems to offer some advantages in terms of duration of surgery ${ }^{5}$ What are the criteria and dimensions below which a PACoA is indicated at the initial palliation?

All of these questions remained unanswered, partially limiting the clinical influence of this well-designed study. We may compare PACoA with a broken vessel, but whether or not PA plasty is the gold dust that restores PA beauty until the definitive repair remains an unanswered question. When to treat the PACoA remains at the surgeon's discretion, knowing that whatever we do, we leave a gold dust scar that may not always donate beauty.

\section{References}

1. Kotani Y, Kobayashi Y, Kadowaki S, Kisamori E, Kobayashi J, Kawabata T, et al. Impact of pulmonary artery coarctation on pulmonary artery growth and definitive repair following modified Blalock-Taussig shunt. J Thorac Cardiovasc Surg. 2022; $163: 1618-26$.

2. Elzenga NJ, von Suylen RJ, Frohn-Mulder I, Essed CE, Bos E, Quaegebeur JM Juxtaductal pulmonary artery coarctation. An underestimated cause of branch pulmonary artery stenosis in patients with pulmonary atresia or stenosis and a ventricular septal defect. J Thorac Cardiovasc Surg. 1990;100:416-24.

3. Cresalia NM, Armstrong AK, Romano JC, Norris MD, Yu S, Rocchini AP, et al Long-term outcomes after surgical pulmonary arterioplasty and risk factors for reintervention. Ann Thorac Surg. 2018;105:622-8.

4. Vida VL, Lo Rito M, Zucchetta F, Biffanti R, Padalino MA, Milanesi O, et al. Pulmonary artery branch stenosis in patients with congenital heart disease. $J$ Card Surg. 2013;28:439-45.

5. Meot M, Lefort B, El Arid JM, Soulé N, Lothion-Boulanger J, Lengellé F, et al Intraoperative stenting of pulmonary artery stenosis in children with congenital heart disease. Ann Thorac Surg. 2017;104:190-6. 